\title{
Migrações em espaços contemporâneos: integração ou pluralismo cultural
}

Vania Herédia ${ }^{1}$

Uma das características fundamentais do fenômeno da imigração é que, fora algumas situações excepcionais, ele contribui para dissimular a si mesmo sua própria verdade (ABDELMALEK SAYAD).

\section{Resumo}

O presente estudo traz para a discussão o tema das migrações internacionais recentes que se diferenciam das migrações históricas numa cidade que foi constituída por processos migratórios no final do século XIX. Propõe uma reflexão sociológica acerca do pluralismo cultural que geram, ao invés da integração pelo processo de assimilação ocorrido no passado. A pesquisa exploratória, de natureza qualitativa, utiliza como referencial teórico autores que estudam as migrações como Sayad (1998), Ambrosini (2011), Trindade (2006), Elias e Scotson (2000) e Santos (2005). Os resultados apresentados nasceram de uma pesquisa que foi realizada pelo Núcleo de Estudos Migratórios da Universidade de Caxias do Sul em parceria com o Centro de Atendimento ao Migrante (CAM) que traçou o perfil de grupos étnicos que se instalaram na cidade de Caxias do Sul/RS e fizeram registro no CAM entre 2014-2018. A análise descritiva mostra que cada grupo étnico possui um perfil distinto, e que, independente da etnia existem dificuldades de inserção em cidades que foram também constituídas por migrações antigas. As condições sociais que caracterizaram cada grupo étnico evidenciam a presença de preconceitos culturais que os migrantes internacionais, principalmente os senegaleses e haitianos enfrentaram numa terra de migrantes históricos. A contribuição do estudo mostra que as dinâmicas migratórias são distintas enquanto muitas situações que o estrangeiro enfrenta sejam semelhantes.

Palavras-chave: Migrações internacionais. Experiências migratórias. Migrações recentes. Globalização.

\begin{abstract}
This study brings to the discussion the theme of recent international migrations that differ from historical migrations in a city that was constituted by migratory processes in the late nineteenth century. It proposes a sociological reflection on the cultural pluralism they generate, rather than integration through the process of assimilation that occurred in the past. The exploratory research, of qualitative nature, uses as reference theoretical authors who study the migrations as Sayad (1998), Ambrosini (2011), Trindade (2006), Elias and Scotson (2000) and Santos (2005). The results presented were born from a research that was carried out by the Center for Migration Studies of the University of Caxias do Sul in partnership with the Migrant Assistance Center (CAM) that outlined the profile of ethnic groups that settled in the city of Caxias do Sul / RS and registered in CAM, between 2014-2018. The descriptive analysis shows that each ethnic group has a distinct profile, and that, regardless of ethnicity, there are difficulties of insertion in cities that were also constituted by old migrations. The social conditions that characterized each ethnic group show the presence of cultural prejudices that international migrants, especially the Senegalese and Haitians, faced in a land of historical migrants. The contribution of the study shows that migratory dynamics are different while many situations that the foreigner faces are similar.
\end{abstract}

Keywords: International migrations. Migratory experiences. Recent migrations. Globalization.

\footnotetext{
${ }^{1}$ Doutora em História das Américas e Pós-doutora em História Econômica. Professora do Programa de PósGraduação em História da Universidade de Caxias do Sul (UCS). vheredia@zaz.com.br
} 


\section{Introdução}

O campo dos estudos migratórios é cada vez mais fecundo uma vez que os fenômenos que dele fazem parte crescem e refletem questões das sociedades contemporâneas. Isso não significa anular a ideia de que o homem sempre se movimentou em busca de condições de vida.

Nas últimas décadas houve um acentuado crescimento das migrações internacionais para o Brasil e devido ao contexto da globalização econômica, muitas comunidades foram obrigadas a deixar seus países de origem. Além das causas políticas e econômicas que tem como prática a expulsão de partes da população mundial de seus locais de origem onde existem conflitos permanentes, encontram-se também os deslocamentos provocados por questões ambientais. A crise econômica que afetou duramente a Europa e os Estados Unidos, na primeira década do século XXI, destino de milhares de migrantes, modificou a rota, já que os pontos atrativos foram sendo substituídos por outros à medida que avançava a crise do capitalismo central. A reorganização da divisão internacional do trabalho no século XXI colocou o Brasil numa dimensão de desenvolvimento em patamares distintos de outros países da América Latina.

Nesse estudo trataremos as migrações na concepção de Ambrosini (2011, p. 10) que define "como um fenômeno social global que perpassa nossa sociedade e a transforma, pondo em discussão diversos fundamentos implícitos no pacto da convivência". Falar de "pacto de convivência" não é tão simples, pois implica na questão de refletir sobre vantagens e prejuízos, controlados pela sociedade receptora, o que nem sempre é compreendido no sentido maior da palavra. Ambrosini usa a concepção de "comunidades imaginadas" de Anderson quando diz que:

a formação das nações modernas codificou e promoveu ativamente a ideia de comunidades imaginadas em que as irmandades entre os membros é acompanhada da distinção de estranhos; uma distinção que se torna cada vez mais difícil e controversa quando os estranhos se inserem no território nacional nas vestimentas de imigrantes, de várias maneiras exigidas pelas sociedades receptoras (ANDERSON, 1996 apud AMBROSINI, 2011, p. 10). 
O autor comenta que as migrações nos obrigam a reescrever o pacto que nos une, adaptando-o a uma sociedade que está se tornando sobre vários aspectos "pós-nacional, pluralística, culturalmente complexa. [...] Observando os outros podemos aprender muito sobre nós mesmos" (AMBROSINI, 2011, p. 10).

Nesse contexto, podemos dizer que "os movimentos internacionais de migração são um fator muito importante para que as sociedades do presente assumam uma natureza multicultural" (TRINDADE, 2006, p. 81). Entretanto, após décadas e décadas de mobilidade, a resistência aparece de forma cada vez mais evidente, e os critérios de recepção nas fronteiras mais rígidas, definem espaços possíveis e impossíveis de mobilidade.

O presente estudo tem como objetivo discutir repercussões de migrações internacionais recentes numa cidade que foi constituída por processos migratórios no final do século XIX. A pesquisa exploratória, de natureza qualitativa, utiliza como referencial teórico autores que estudam as migrações como Sayad (1998), Ambrosini (2011), Trindade (2006), Elias e Scotson (2000) e Santos (2005).

A análise trata de três grupos étnicos que fazem parte do Banco de Dados do Centro de Atendimento ao Migrante, administrado pela congregação scalabriniana em Caxias do Sul. Os perfis desses grupos étnicos foram estabelecidos por meio do cadastro de migrantes registrados nesse Centro.

\section{Pluralismo cultural ou Políticas de assimilação}

A integração de migrantes ou de comunidade de imigrantes em sociedades maioritárias depende das politicas de acolhimento, definidas pelo Estado receptor. Trindade (2006) explicita que as políticas podem ter cunho assimilacionista e ou pluralista, dependendo do interesse expresso nas políticas de Estado.

Segundo a autora, as políticas de cunho assimilacionista estão em desuso, devido ao resultado de experiências que ao invés de promoverem a homogeneização cultural dos imigrantes, fortaleceram a constituição de grupos diversos culturalmente. Nas políticas de cunho pluralistas, evidente em diversos países do Ocidente, aparecem como comunidades que são aceitas, mas exteriorizadas pela sociedade de recebimento, sem promover a 
integração. Esse tipo de política promove o chamado "mosaico cultural" onde é possível a formação de grupos étnicos bem distintos (TRINDADE, 2006).

A questão atual das migrações africanas pode ajudar a explicitar esse raciocínio. Quando se fala de africanos toma-se como aquele continente fosse homogêneo e que as migrações que dele partem fossem todas semelhantes, com as mesmas características e promovidas pelos mesmos fatores. O equivoco começa com a questão muitas vezes enunciada de forma redundante quando a sociedade (a imprensa) descreve aqueles africanos negros, como se todos os migrantes africanos fossem negros e como se todos os africanos fossem do mesmo grupo étnico, com a mesma formação e colonização. Nesse sentido, pergunta-se se o problema é a migração, o lugar de origem ou a questão de raça ou de cor?

Na primeira conferência municipal de Migrações que foi organizada em Caxias do Sul, em 2014, pela Prefeitura Municipal e Universidade de Caxias do Sul, quando inúmeros municípios assim o fizeram para colaborar com o Governo Federal para subsidiar a política nacional de Migrações, observou-se que alguns grupos migratórios internacionais recentes estavam organizados em associações étnicas e suas reivindicações ao governo brasileiro eram muito precisas e objetivas quanto à inserção de seu grupo (étnico) na sociedade local. As reivindicações apontavam para ter garantias de direitos iguais aos demais indivíduos, direitos que acreditam ser universais e que enfrentavam dificuldades de acesso a espaços que atendessem a esses direitos como saúde e educação. A luta era pelas garantias mínimas de segurança e respeito, direitos que são universais. O escopo das reivindicações de grupos migrantes na cidade conduz a seguinte reflexão: para onde estamos caminhando?

Norbert Elias e Scotson (2000) já tratavam da ideia de homogeneidade e de heterogeneidade quando escreveram a obra "Os estabelecidos e os outsiders", pesquisa realizada em uma comunidade industrial inglesa, relativamente homogênea, publicada em 1965. No contexto atual, na sociedade rio-grandense, uma sociedade construída por fluxos migratórios históricos, dialogar acerca de quem são "os estabelecidos" e, de como esses tratam aqueles que vêm de fora, depois deles é fundamental. O que fica claro nas conclusões dos autores, é que os estabelecidos, chamados os primeiros (para nós os pioneiros), estabeleceram sua distinção e o seu poder, baseados no principio de antiguidade, 
ou seja, moravam no lugar muito antes do que os outros, sustentando as tradições (ELIAS, SCOTSON, 2000). Os que chegaram depois eram estigmatizados pelos primeiros, e depois por todos, associando atributos negativos, reflexos de tensão entre a inclusão e a exclusão e a participação e integração não eram espontâneas como ocorreu em grupos anteriores.

\begin{abstract}
Se as diferenças de 'antiguidade' e 'novidade' ainda são raramente percebidas como propriedades referentes a diferenças estruturais dos grupos, isso se deve basicamente ao fato de que o conceito vigente de estrutura social tem uma forte tendência a fazer as pessoas perceberem as estruturas como 'planos fixos', 'como estruturas situacionais permanentes', ao passo que os movimentos das estruturas no tempo, tenham eles a forma do desenvolvimento ou de outros tipos de mudanças sociais, são tratados como 'históricos' (ELIAS, SCOTSON, 2000, p. 59).
\end{abstract}

O texto de Elias e de Scotson (2000) esclarece o papel das categorias analíticas que demonstram as relações de poder na ocupação que ocorre no Brasil, promovida oficialmente pelo Império e depois pela República por aqueles que vêm de fora. Num primeiro momento todos vêm de fora, mas depois que se estabelecem, começam as divisões e as categorizações. Cada sociedade cria explicações para estabelecer as diferenças, os primeiros, os pioneiros, os empreendedores e os outros.

Nesse sentido, é importante na discussão atual acerca das migrações internacionais o processo de assimilação, no qual estamos bastante distantes, pelas condições em que se inserem as migrações recentes, distintas das históricas e refutadas pelos primeiros como se desconhecessem o sentimento daqueles que partem e daqueles que chegam, como se não tivessem tido no passado a experiência da chegada de milhares num país cuja política de imigração os recebeu de braços abertos.

No caso de contextos derivados de culturas migratórias, que para nós, que vivemos no Rio Grande do Sul é bastante frequente, percebemos que existe uma vontade de não anular ou enfraquecer a cultura europeia de origem, por ela ser um elemento identitário bastante forte, não excludente e integrativo. Nesse sentido, mesmo após diversas gerações de descendentes, não se esconde a cultura de origem e procura-se em situações frequentes deixá-la bastante evidente. Mesmo que essas gerações tenham outros hábitos, reafirmam essa relação.

Entretanto, nessa cultura quando chegam outros grupos de fora, não necessariamente estrangeiros, são cobrados pelas diferenças que expressam. Constata-se 
que aqueles que vêm de fora dos grupos, sejam da mesma nacionalidade ou de nacionalidades distintas, sofrem o ônus da cultura que nem sempre permite a integração. Para os mais próximos, menos constrangimento social, para os mais distantes maiores exigências e desconfianças no processo de integração. Trindade (2006) comenta que se

\begin{abstract}
os membros de uma dada comunidade estrangeira apresentarem consistentemente comportamentos que não provoquem atitudes de estranheza ou de rejeição quanto aos seus costumes e modos de actuar, há fortes probabilidades de que venham a ser na generalidade objeto de um juízo neutro ou favorável do gênero: 'são gente pacífica', 'pessoas que não causam problemas', 'é uma comunidade ordeira e trabalhadora', o que significa que se encontram próximos de uma integração com sucesso $(2006$, p. 87).
\end{abstract}

Norbert Elias e Scotson (2000) quando editam "Os estabelecidos e os outsiders" mostram publicamente a diferença existente entre os que chegam primeiro e os que chegam depois. Os mais antigos, como já falamos, se juntam as tradições que os identificam e colocam os demais numa condição de subordinação ou sob a condição de mecanismos de integração definidos pelos estabelecidos. É o caso, por exemplo, na região de Caxias do Sul, quando a migração dos Campos de Cima da Serra começa a ser intensa e contínua, após a metade do século $\mathrm{XX}$, as indústrias criam mecanismos de integração por meio de grupos, de tradição gaúcha, facilitando a integração, mas garantindo a existência das diferenças.

Então quais são as preocupações com os migrantes quando começam os movimentos de resistência em relação a eles? Quais são as preocupações que giram em torno do tema e porque os homens acreditam que não exista mais lugar para os que vêm de fora e que não necessariamente estão dispostos a incorporar a cultura do estabelecido?

Boaventura dos Santos quando analisa os efeitos dos processos de globalização que ocorreram no mundo a partir da última década no século XX explica que

a globalização das últimas três décadas, em vez de se encaixar no padrão moderno ocidental de globalização - globalização como homogeneização e uniformização sustentado por Leibitz, como por Marx, tanto pelas teorias de modernização, como pelas teorias do desenvolvimento dependente, parece combinar a universalização e a eliminação das fronteiras nacionais, por um lado, o particularismo, a diversidade local, a identidade étnica e o regresso ao comunitarismo, por outro (SANTOS, 2005, p. 26). 
Essa afirmação parece que não ocorreu como previsto, no sentido de a globalização promover uma homogeneização à medida que a diferença entre pobres e ricos ficou mais visível e segundo ele mesmo a migração internacional tornou-se um fenômeno massivo, gerado por inúmeras causas desse processo, ou seja:

catástrofes ambientais, conflitos étnicos, sobrepopulação, emergência de novos estados e falência de outros, proliferação das guerras civis, crime globalmente organizado e a democracia formal como uma condição política para a assistência internacional (SANTOS, 2005, p. 26).

No contexto colocado por Boaventura dos Santos, não apenas os de fora estão ameaçados, mas também a cultura da sociedade local enfrenta ameaças frente à força das sociedades globais. No enfrentamento dessas duas forças, como se analisa a questão migratória que nasce desse movimento, feito pelo capital como uma nova divisão do trabalho, onde ricos e pobres se separam e onde o capital não tem fronteiras, mas o trabalho sim. Quem escolhe os destinos? Que informações são geradas para a escolha dos destinos? Como são tratados esses movimentos, à medida que não existe possibilidade de retorno para alguns desses grupos.

Podemos explicitar essa afirmação a partir dos estudos que realizamos na Universidade de Caxias do Sul, no Núcleo de Estudos Migratórios, comparando três dos diversos grupos étnicos. A análise desses três grupos étnicos (senegaleses, haitianos e ganeses) que chegaram a Caxias do Sul em 2014, período ainda favorável a economia brasileira, evidencia as semelhanças e as diferenças das escolhas do destino e o perfil de cada grupo.

\section{Senegaleses, haitianos e ganeses}

O caso dos senegaleses apresenta uma migração laboral cujo perfil dos migrantes corrobora com o tipo de migração. Os senegaleses que procuram a cidade de Caxias do Sul são jovens, alfabetizados, com escolaridade média, muçulmanos, em busca de trabalho, solteiros, provenientes de pequenas cidades do interior do Senegal, escolhidos pela família para migrar. Constata-se que esses migrantes dispunham informações sobre ocupação, em locais do estado que já empregavam senegaleses, principalmente para tipos específicos de 
trabalho como os frigoríficos, construção civil, metalúrgicas entre outros. Os senegaleses se movimentam em busca de trabalho e o motivo da migração é o sustento da família na sociedade de origem. Os senegaleses falam francês e o "wolof"2.

Vale lembrar, utilizando o estudo feito por Tedesco e Grzybovski, realizado em 20092011, que muitos senegaleses foram agenciados por empresários do corte de aves para trabalho em frigoríficos com intuito de garantir o ritual Halal na exportação de carnes de aves para os países árabes. Nos estudos de Tedesco e Grzybovski (2013) acerca dos senegaleses em Passo Fundo, as informações que expressam o motivo do deslocamento são:

[...] todos entrevistados são islâmicos e, assim, passam a ser mão de obra demandada pelos frigoríficos exportadores de carnes de aves aos países árabes, os quais requerem a certificação Halal (TEDESCO; GRZYBOV, 2013, p. 319).

[...] Os motivos de estes imigrantes estarem em Passo Fundo são variados, mas a maioria deslocou-se de São Paulo, após receber informações de conterrâneos que estavam trabalhando num abatedouro de aves em Nova Araçá. A informação que passou a circular entre imigrantes senegaleses, em âmbito nacional é que em Passo Fundo seria possível agilizar a documentação para a estada provisória no país (TEDESCO; GRZYBOV, 2013, p. 319).

Esses dados mostram o que foi dito anteriormente, ou seja, que as fronteiras estão abertas quando existe a necessidade de ocupação de mão de obra com interesses demarcados pelo capital. Entretanto, à medida que começa o deslocamento maior que o desejado e necessário, nem sempre é possível controlá-lo.

Nesse sentido, constata-se que a vinda de grupos para o trabalho, pode ter sido estímulo para a escolha do destino. O percurso de viagem é bastante longo para os senegaleses. A saída de Dakar para Madrid, depois Quito com duas opções, uma via Lima/ Peru e outra via Cobija/Bolívia, com ingresso por Basiléia. O custo da viagem é alto e para aqueles que não possuem documentação apresenta riscos. A entrada para o Brasil pelo Acre, por Basiléia deve-se ao fato do controle da documentação.

Segundo Uebel (2016, p. 60), “a escolha do ingresso por Basileia, Acre, dá-se pelo fato que lá estes imigrantes ou ingressavam de forma irregular, indocumentados, ou solicitavam refúgio, alegando perseguições políticas no Senegal". Para entendermos a migração laboral é importante lembrar que o salário de renda nos países dos quais partem

\footnotetext{
${ }^{2}$ VER HERÉDIA, V.B.M. Migrações internacionais: o caso dos senegaleses no sul do Brasil. Caxias do Sul: Quatrilho, 2015.
} 
os imigrantes é muito baixo, o que permite, quando conseguem trabalho regular, enviar recursos para suas famílias.

Para termos uma noção a renda média mensal de um salário mínimo brasileiro entre 2013 e 2015, quando foi feita a pesquisa era de $R \$ 788,00,3,4$ vezes maior que o salário mínimo senegalês que era em 2013 que era de 36.244 francos (moeda oficial do Senegal), aproximadamente R\$232,00 (UEBEL, 2016, p. 60).

As remessas de dinheiro para os países de onde partiram são dados relevantes nos estudos migratórios sejam em migrações antigas sejam nas recentes. Eles mostram em números os motivos econômicos, e ao que se submetem no mundo do trabalho pela condição de migrantes para enviarem recursos monetários para as famílias.

O caso dos haitianos, já tem uma conotação distinta dos senegaleses, principalmente quando o motivo da migração é causado por uma catástrofe ambiental e a população atingida não tem como permanecer no país. Os migrantes não são apenas jovens e não são apenas homens. Migram com as famílias o que os difere dos senegaleses. São evangélicos e católicos, amparados por acordos diplomáticos, que foram assinados por governos anteriores, que legitimam a entrada no país de forma legal. Muitos entram no país com o visto humanitário.

Nesse contexto é importante distinguir o que significa o conceito de refugiado e quando se aplica essa situação. Refugiados são "aquelas pessoas que são forçadas a fugirem de seus países, individualmente ou parte de evasão em massa, devido a questões políticas, religiosas, militares ou quaisquer outros problemas" (UEBEL, 2016, p. 60).

Os haitianos são estimulados a migrar para o Brasil, inclusive por soldados brasileiros que estavam na Missão de $\mathrm{Paz}^{3}$ no Haiti quando do terremoto. A escolha do destino não foi simples, mas muitos acreditaram que teriam todos os direitos assegurados de participar da

\footnotetext{
${ }^{3}$ É importante lembrar que em junho de 2004 havia sido feita uma resolução 1542 do Conselho de Segurança da Organização das Nações Unidas, chamado MINUSTAH, ou seja, Missão de Estabilização das Nações Unidas no Haiti, que foi liderada pelo Brasil para restabelecer a ordem no país por meio de um mandato em três áreas principais: provimento de segurança e de um ambiente estável, particularmente através do desarmamento; apoio ao processo político e a boa governança, em preparação para eleições futuras eleições, previstas para novembro de 2005; e monitoramento e apresentação de relatório sobre direitos humanos (BARBOSA, 2015, p.c23). Os 'casque bleus' são "forças de manutenção da paz das Nações Unidas. Conhecidos como - Capacetes Azuisll (em inglês, United Nations Peacekeeping Forces) são forças militares multinacionais instituídas pela Organização das Nações Unidas, com a aprovação e objetivos designados pelo Conselho de Segurança das Nações Unidas, para atuar em zonas de conflito armado" (BARBOSA, 2015, p. 24).
} 
vida politica e econômica do país devido ao acordo diplomático, o que não assegurava essa participação. Nesse sentido, os haitianos, pelo menos em Caxias do Sul, apresentam maiores dificuldades de inserção do que os senegaleses mesmo que os primeiros não pudessem retornar e os segundos tivessem essa opção. Os haitianos dispunham do visto humanitário e os senegaleses, a condição de refugiados.

A entrada dos haitianos foi mais acessível mesmo que muitos também sofreram discriminação e preconceito na chegada devido à cor e não ao grupo étnico. Após o terremoto que abalou o pequeno país do Caribe, em janeiro de 2010, uma parte de sua população decidiu migrar para sobreviver ${ }^{4}$.

A saída para muitos é via República Dominicana, depois Panamá, Equador, Peru para chegar ao Brasil pelo Acre. Começam a entrar no Brasil, pelas vias fronteiriças, particularmente "[...] na região dos municípios da Brasiléia [...] no estado do Acre, na fronteira com a Bolívia, e a na Cidade de Tabatinga [...], no Amazonas, fronteira com a Colômbia e com o Peru" (ALCANTARA, 2014, p. 36). Muitos fazem a travessia por via terrestre por não possuírem a documentação correta ou serem indocumentados ${ }^{5}$.

\footnotetext{
${ }^{4} \mathrm{O}$ saldo do terremoto foi "de 200 mil mortos e 300 mil desabrigados e feridos [...] Dez meses após o terremoto, surge um surto de cólera no final de outubro de 2010, na área rural do Departamento de Artibonite, cerca de $100 \mathrm{~km}$. de Porto Príncipe. Na época 680 mil haitianos foram infectados pela cólera e 8.000 mil morreram" (BARBOSA, 2015, p. 13-14). Os haitianos que tem chegado ao país não são imbuídos do status de refugiados por não terem sido perseguidos em seu país (BARBOSA, 2015, p. 14).

${ }^{5}$ As solicitações dos haitianos são encaminhadas ao Conselho Nacional de Imigração (CNig), órgão do governo federal que concede ao grupo, desde 2010, um visto especial humanitário, que lhes dá proteção internacional e os mesmos direitos garantidos aos refugiados. Mais de 25 mil imigrantes já entraram no Brasil, desde dezembro de 2010, segundo dados dos governos federal e do Acre. Em média, 50 imigrantes chegam diariamente ao Acre e são enviados para São Paulo em ônibus fretados pelo governo estadual do Acre. Alguns gastaram até quatro mil dólares com coiotes e chegaram ao Brasil em situação de vulnerabilidade social, sanitária e de saúde (BARBOSA, 2015, p. 14). A partir de uma resolução normativa do Conselho Nacional de Imigração, foram concedidos cerca de dez mil vistos humanitários com validade de cinco anos, documento que pode ser obtido nas embaixadas do Brasil na capital do Haiti, Porto Príncipe, em Lima, no Peru, e em Quito, no Equador. A concessão do visto humanitário, conforme Godoy (2010) demonstra a abertura do Brasil diante dos problemas da humanidade em nível global, os refugiados ambientais, situação em que se enquadra o "visto humanitário" concedido pelo governo brasileiro aos refugiados ambientais haitianos (BARBOSA, 2015, p. 15). De acordo com Godoy (2010 p. 63-65): "No que se refere ao tratamento conferido aos haitianos que solicitam refúgio no Brasil, o denominado 'visto humanitário' é uma interessante ferramenta de proteção complementar e tal prática tem - potenciais enormes a serem revelados. $O$ 'visto humanitário' concedido aos haitianos no Brasil pretende ser uma resposta complementar frente ao deslocamento de pessoas vítimas dos efeitos dos desastres naturais [...]. Propõe-se que a devolução ao país de origem e as deportações em massa não sejam levados a cabo, especialmente levando-se em conta a peculiar situação do Haiti, o dispositivo do art. 70 do Pacto Internacional dos direitos civis e políticos e as obrigações gerais de 'non-refoulement' contidos nos demais tratados internacionais do qual o país faz parte" (BARBOSA, 2015, p. 15).
} 
Os haitianos falam o francês e o "crioulo" e as remessas para os familiares são entre U\$100 e U\$150 dólares, quando os salários desses imigrantes variam entre $R \$ 1.200$ e $R \$$ 1.500 reais mensais. "No Haiti, um dólar americano corresponde a 40 gourdes. 0 restante do salário dos imigrantes é destinado para despesas mensais [...] A cada $\mathrm{R} \$ 500$ reais enviados ao exterior, os haitianos pagam uma taxa de R\$ 98 reais, então, esperam, às vezes, três meses para remeter recursos às famílias (BARBOSA, 2015, p. 32).

O caso dos ganeses que chegaram a Caxias em julho de 2014 também tem história. Esse grupo que entrou no país com visto turístico, a fim de assistir aos jogos da Copa do Mundo, no término, pede refugio no Brasil. O deslocamento para Caxias, no inverno de 2014, deu-se em busca dos papeis da documentação necessária para o visto humanitário. Os ganeses são outra experiência migratória. Não querem retornar ao país de origem, mas também suas intenções não são permanecer em Caxias do Sul, no Brasil. O sonho do destino final era a América, mas a do Norte e não a do Sul.

Nesse sentido, constata-se que esses deslocamentos movimentam grupos que aspiram ter uma vida melhor, com perspectiva, que o trabalho valha a pena que o mundo tenha um sentido positivo em suas buscas. O perfil dos ganeses era jovens, homens, solteiros, com escolaridade média e superior, falam fluentemente o inglês e buscam um destino que lhes garanta futuro. As experiências que trouxeram consigo de seu país de origem eram experiências no comércio, atividades artesanais urbanas como encanador, sapateiros, açougueiro, professor, motorista, mecânico e alguns jogadores de futebol. Os três grandes motivos de migração apresentados pelos ganeses eram: a busca de trabalho, perseguição política e trabalho familiar. Para permanecerem em Caxias necessitavam preencher o protocolo de refugio, cujo auxilio foi proporcionado por inúmeros sujeitos da comunidade de Caxias, como padres, seminaristas, profissionais do Centro de Atendimento ao Migrante, alunos da universidade, empresários e voluntários. Os ganeses foram ajudados por esses a fim de que pudessem preencher os protocolos junto a Polícia Federal com objetivo de encaminhar o pedido de refúgio. 
Nos três casos constata-se que a decisão de migrar é uma decisão que tem a ver com a busca de melhores condições de vida, mas não apenas para aqueles que migram, mas para aqueles que dele dependem. Nas histórias desses três grupos, a migração faz parte de suas histórias e tem sentido quando explicam que deles depende a sobrevivência do grupo que permaneceu no país de origem. Fica evidente que tudo depende da recepção da imigração, "da capacidade de gerenciar os processos sociais que dela dependem bem como da representação social que a sociedade de acolhimento faz dela, como um fenômeno ameaçador e incontrolável ou um processo fisiológico e governável" (AMBROSINI, 2011, p. 11). Em nenhum dos casos ocorre a assimilação, ao contrário, as culturas dos migrantes são distintas e colaboram para o fenômeno da multiculturalidade, quando as culturas se entrelaçam, mas mantêm suas diferenças.

\section{Algumas considerações}

As políticas de migração são definidas pelas políticas de governo e refletem muitas vezes posições diversas dos agentes que intermediam essas posições. Nem sempre as posições políticas convergem na sua integra com as posições dos representantes econômicos.

Os jogos de poder que entrelaçam essas posições mostram os envolvidos, os seus interesses e as forças que representam. As restrições que controlam a mobilidade humana nos países que oferecem maiores benefícios levam em consideração: a política externa relações de vizinhança, as representações, os interesses econômicos, preocupações com segurança, pressões das organizações não governamentais, influência das instituições políticas internacionais e acordos entre governos.

Nesse estudo de caso, dos migrantes internacionais que buscaram uma cidade média para se instalar, refletem que o processo de assimilação não acontece pelo fato de os migrantes não estarem preocupados em garantir a inserção pela troca de costumes e práticas culturais. Esses grupos buscam a inserção sem afetar suas identidades étnicas e conseguem se movimentar mantendo hábitos, costumes e práticas da sociedade de origem. Os senegaleses, por exemplo, no que concerne a religião, fazem seus cultos em lugares que 
conseguem e muitas das suas festas foram realizadas em salões de paroquias que são utilizados para encontros paroquiais. Os haitianos dedicam-se as práticas religiosas, separados dos demais e até conseguiram ter espaços próprios para os cultos.

Constata-se nessas pesquisas que a migração internacional que busca a cidade de Caxias do Sul como destino tem um caráter laboral. Os dados corroboram com o pensamento de Sayad quando o autor postula que a migração se dá quando os indivíduos se movimentam em busca de trabalho. "O imigrante só existe na sociedade que assim o denomina a partir do momento em que atravessa suas fronteiras e pisa seu território; o imigrante nasce nesse dia para a sociedade que assim o designa" (SAYAD, 1998, p. 16). A explicação dada por Sayad ao imigrante quando o mesmo é reconhecido como tal mostra que "na medida em que a presença do imigrante é uma presença estrangeira ou que é percebida como tal, as "ilusões" que a ela estão associadas e que até mesmo a constituem podem ser enunciadas como sempre" (SAYAD, 1998, p. 18). Essas ilusões, segundo Sayad que tornam o imigrante um ser provisório.

O papel das redes é muito importante na inserção dos migrantes mesmo que sejam utilizadas de forma distinta. Para os haitianos, as redes familiares são muito fortes e podem até ser uma característica do grupo. Para os senegaleses também as redes familiares aparecem como um elemento que constitui o processo de migração, principalmente quando escolhem o membro da família e ajudam financeiramente as despesas da viagem com intuito de colaboração para aquele que migra pelo grupo.

O debate migratório traz para a discussão os problemas que as migrações de trabalho enfrentam nos negócios onde se inserem, expostos a precariedade, com significativa difusão de relações de trabalho irregulares, situações que nem sempre, os do local aceitariam, de forma normal e corriqueira. Nesse sentido, as categorias dos estabelecidos e os de fora ajudam a entender a ambiguidade e os paradoxos que o migrante enfrenta quando chega à sociedade de destino, e precisa aceitar as regras para sua inserção. 


\section{Referências}

ALCÂNTARA, P. I. M. Novas fronteiras: um olhar sobre a migração haitiana para o Brasil. Brasília: Universidade de Brasília, 2014.

AMBROSINI, Maurizio. Sociologia delle migrazioni. 2. Ed. Bologna: Mulino, 2011.2.

BARBOSA, Lorena S. Imigrantes haitianos no Rio Grande do Sul: uma etnografia de sua inserção no contexto sociocultural brasileiro. 2015. Dissertação (Mestrado) - Universidade Federal de Santa Maria, Santa Maria, 2015.

ELIAS, Norbert, SCOTSON, John L. Os estabelecidos e os outsiders. Rio de Janeiro: Zahar, 2000.

HERÉDIA, Vania B.M. Migrações internacionais: o caso dos senegaleses no sul do Brasil. Caxias do Sul: Quatrilho, 2015.

SANTOS, B. S. S. A globalização e as ciências sociais. 3. ed. São Paulo: Cortez, 2005.

SAYAD, Abdelmaleck. A Imigração ou os paradoxos da alteridade. São Paulo: Edusp, 1998.

TEDESCO, João Carlos; GRZYBOVSKI, Denise. Dinâmicas migratórias dos senegaleses no norte do Rio Grande do Sul. In: R. Bras. Est. Pop., Rio de Janeiro, v. 30, n. 1, p. 317-324, jan./jun. 2013.

UEBEL, Roberto Rodolfo Georg. Panorama e perfil da imigração senegalesa no Rio Grande do Sul no início do século XXI. In: Boletim Geográfico do Rio Grande do Sul, Porto Alegre, n. 28, p. 56-77, set. 2016.

TRINDADE, Maria Beatriz Rocha. Recriação de identidades em contextos de migração. In: LUCENA, Célia Toledo; GUSMÃO, Neusa Maria Mendes de (orgs.) Discutindo identidades. São Paulo: Humanitas/CERU/2006, p.75-90. 